\title{
Tests of the Stability of Chinese RhFe Resistance Thermometers at Low Temperatures
}

\author{
A. Kowal ${ }^{1}$ - H. Manuszkiewicz ${ }^{1}$ - B. Kołodziej ${ }^{1}$. \\ A. Szmyrka-Grzebyk ${ }^{1}$ - Peng $\mathrm{Lin}^{2} \cdot \mathrm{Bo} \mathrm{Gao}^{2}$. \\ Lihong $\mathrm{Yu}^{2}$
}

Received: 25 August 2016/ Accepted: 9 April 2017 / Published online: 25 April 2017 (C) The Author(s) 2017. This article is an open access publication

\begin{abstract}
Rhodium-iron resistance thermometers are recommended as precise thermometers at temperatures below $25 \mathrm{~K}$. The thermometers were developed at the National Physical Laboratory and produced by H. Tinsley and Co Ltd almost 50 years ago. Later, they were made by other companies and institutes as well, but despite this, the availability of the thermometers decreased and a new source of supply was needed. Several years ago, the Technical Institute of Physics and Chemistry (TIPC), Chinese Academy of Sciences, developed its own technology for making wire of Rh- 0.5 at $\%$ Fe alloy which was used in the production of new thermometers. These devices have been tested previously at INRIM (Italy) and later at INTiBS (Poland). INTiBS has carried out an investigation focused on the thermometers' stability after thermal cycling treatment. This paper presents the results of stability tests of about 30 thermometers produced by TIPC in two batches. The resistance of each thermometer was measured at temperatures of about $4.6 \mathrm{~K}$ and $7.2 \mathrm{~K}$ before and after 10,30 and 50 thermal cycles from room temperature. The methods of measurement and the design of the cryostat used for the research are also presented.
\end{abstract}

Keywords Cryogenic thermometers - Resistance thermometers · Rhodium-iron thermometers - Thermometer stability

Selected Papers of the 13th International Symposium on Temperature, Humidity, Moisture and Thermal Measurements in Industry and Science.

$\triangle \quad$ A. Kowal

a.kowal@int.pan.wroc.pl

1 Instytut Niskich Temperatur i Badań Strukturalnych PAN, Wrocław, Poland

2 Technical Institute of Physics and Chemistry, Chinese Academy of Sciences, Beijing, People's Republic of China 


\section{Introduction}

The history of rhodium-iron resistance thermometers (RIRTs) extends for almost 50 years [1]. Due to their anomalous resistance versus temperature characteristics, they can be used for accurate temperature measurement at low temperatures, where platinum resistance thermometers become unusable because of low sensitivity. RIRTs were developed by R. Rusby at National Physical Laboratory and produced by $\mathrm{H}$. Tinsley and Co Ltd in the early 1970s [2,3]. Later, they were produced by other companies and institutes [4-6], but despite this the availability of the thermometers decreased and a new source of supply was needed. Several years ago, the Technical Institute of Physics and Chemistry (TIPC), Chinese Academy of Sciences, developed its own technology for making wire of Rh- 0.5 at\% Fe alloy which was used in the production of new thermometers $[7,8]$. The construction of the thermometers is the same as capsule-type standard platinum resistance thermometers. The properties of the RIRTs were initially studied at INRIM and then at INTiBS at the end of the last decade $[9,10]$. Recently, after improvement of the thermometer production technology, about 30 thermometers produced by TIPC in two batches were tested at INTiBS. Between 2012 and 2013, RIRTs with the numbers shown in Table 1 were tested. The next batch, with the numbers shown in Table 2, was tested during the period 2014-2016.

This study is focused on measurements of the thermometer's resistance after 50 thermal cycles between room temperature and liquid helium temperatures. The resistance of each thermometer was measured at about $4.6 \mathrm{~K}$ and $7.2 \mathrm{~K}$ before the thermal treatment and after 10, 30 and 50 thermal cycles.

\section{Thermal Treatment}

For the thermal cycling treatment, the thermometers were mounted in a sealed stainless steel container made of a tube with a diameter of $25 \mathrm{~mm}$ and a length of $130 \mathrm{~cm}$. The container was pumped to about $0.1 \mathrm{~Pa}$ pressure and then filled with gaseous helium to ensure a good thermal exchange between thermometers and liquid helium. The container was dipped slowly into liquid helium to cool the thermometers to $4.2 \mathrm{~K}$ over about $5 \mathrm{~min}$. Then, it was removed from the helium Dewar, and the thermometers warmed to room temperature. The procedure was repeated 10 times initially and then 20 times in each of two subsequent runs. After each treatment, the thermometers were inserted into the copper block of a cryostat for measurement.

\section{Cryostat Construction}

A liquid helium cryostat developed at INTiBS, shown in Fig. 1, was used for the investigation. It was equipped with an adjustable thermal switch, $a$, mounted between the helium container, LHe, and the copper block, $b$. The heat switch was based on the dependency of the thermal conductivity of gaseous helium on pressure.

Nine thermometers from TIPC and the reference rhodium-iron thermometer B178 from Tinsley, which participated in the EURAMET.T-K1 key comparison [8], were mounted in the isothermal copper block, $b$. The copper block was surrounded by 


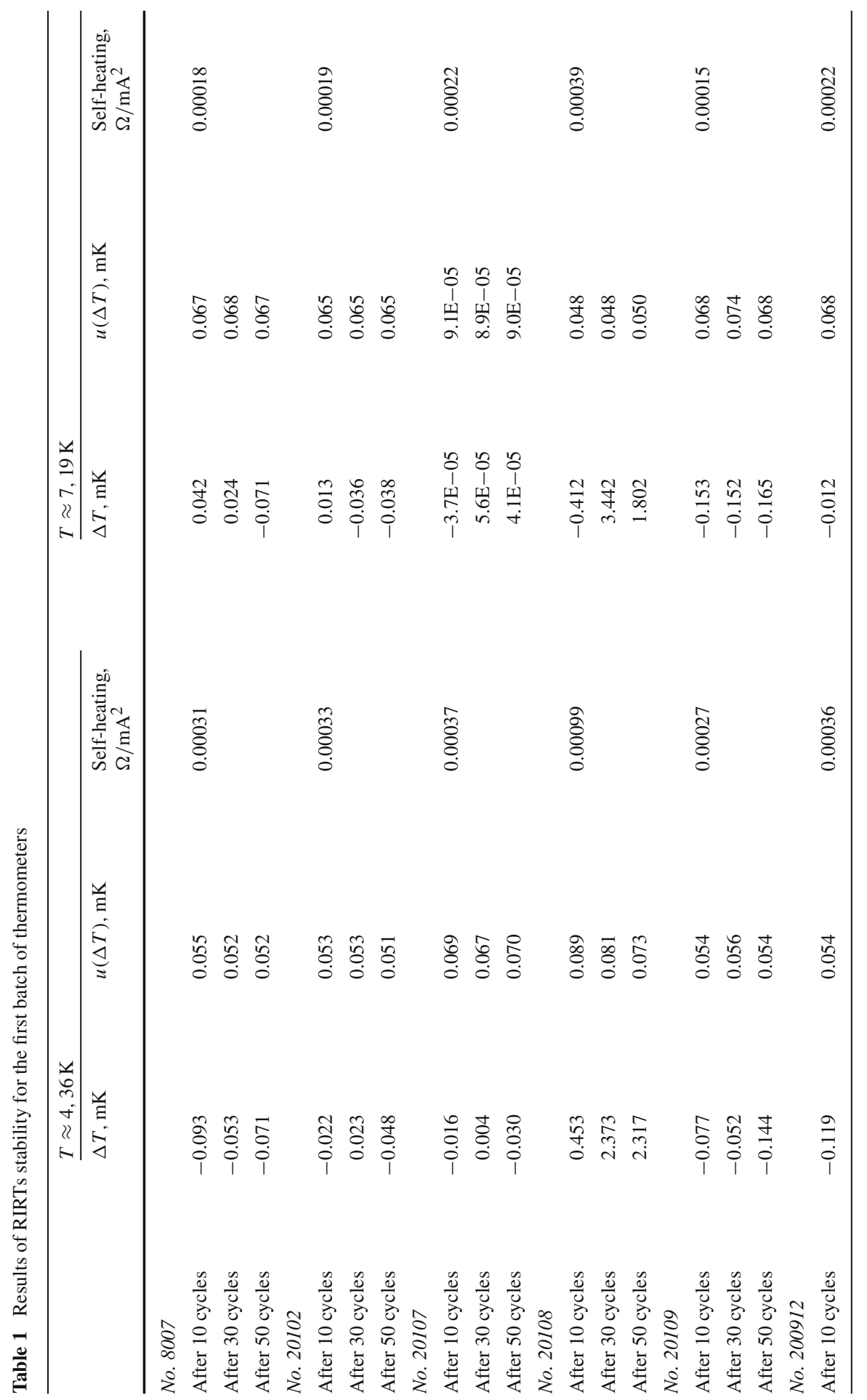




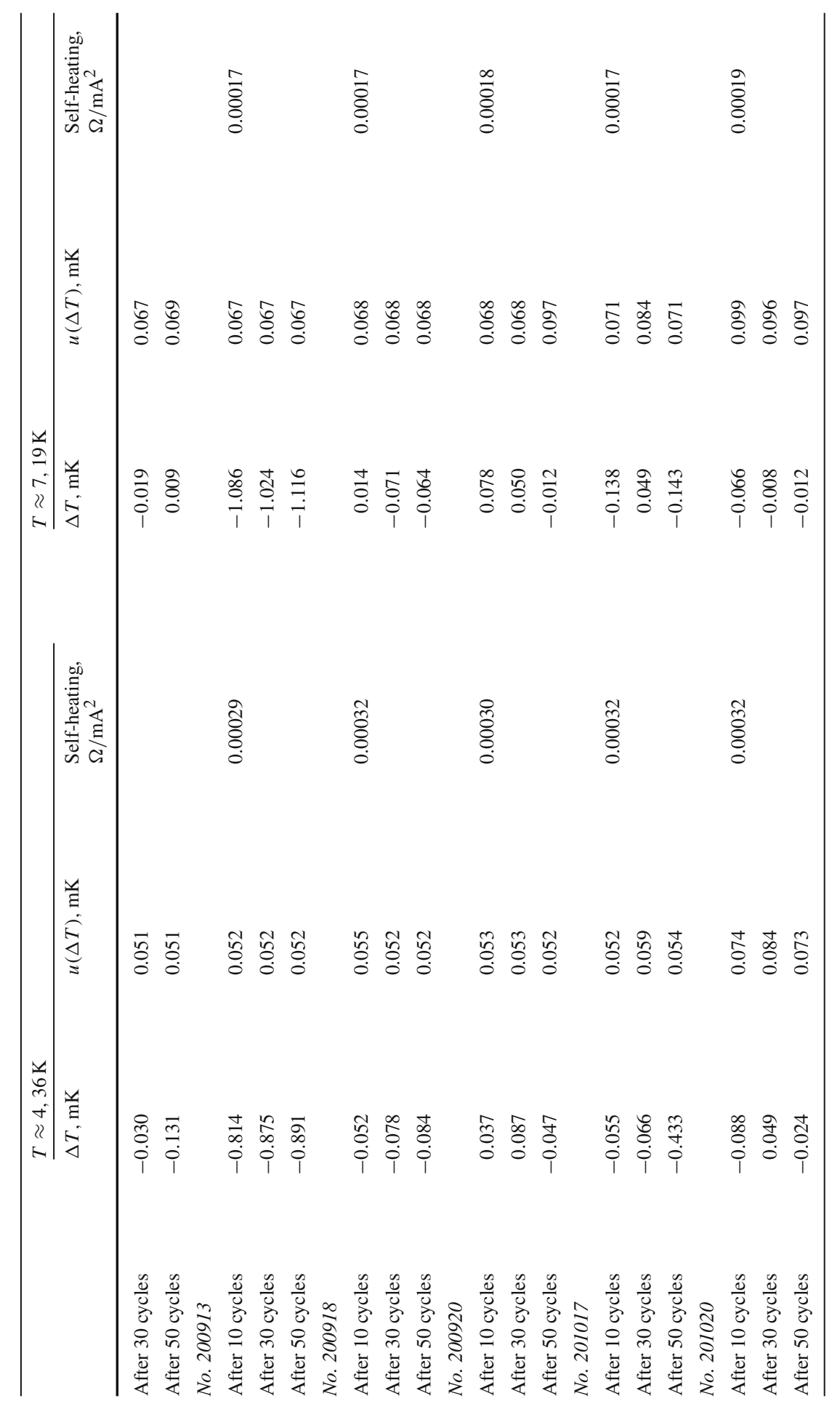




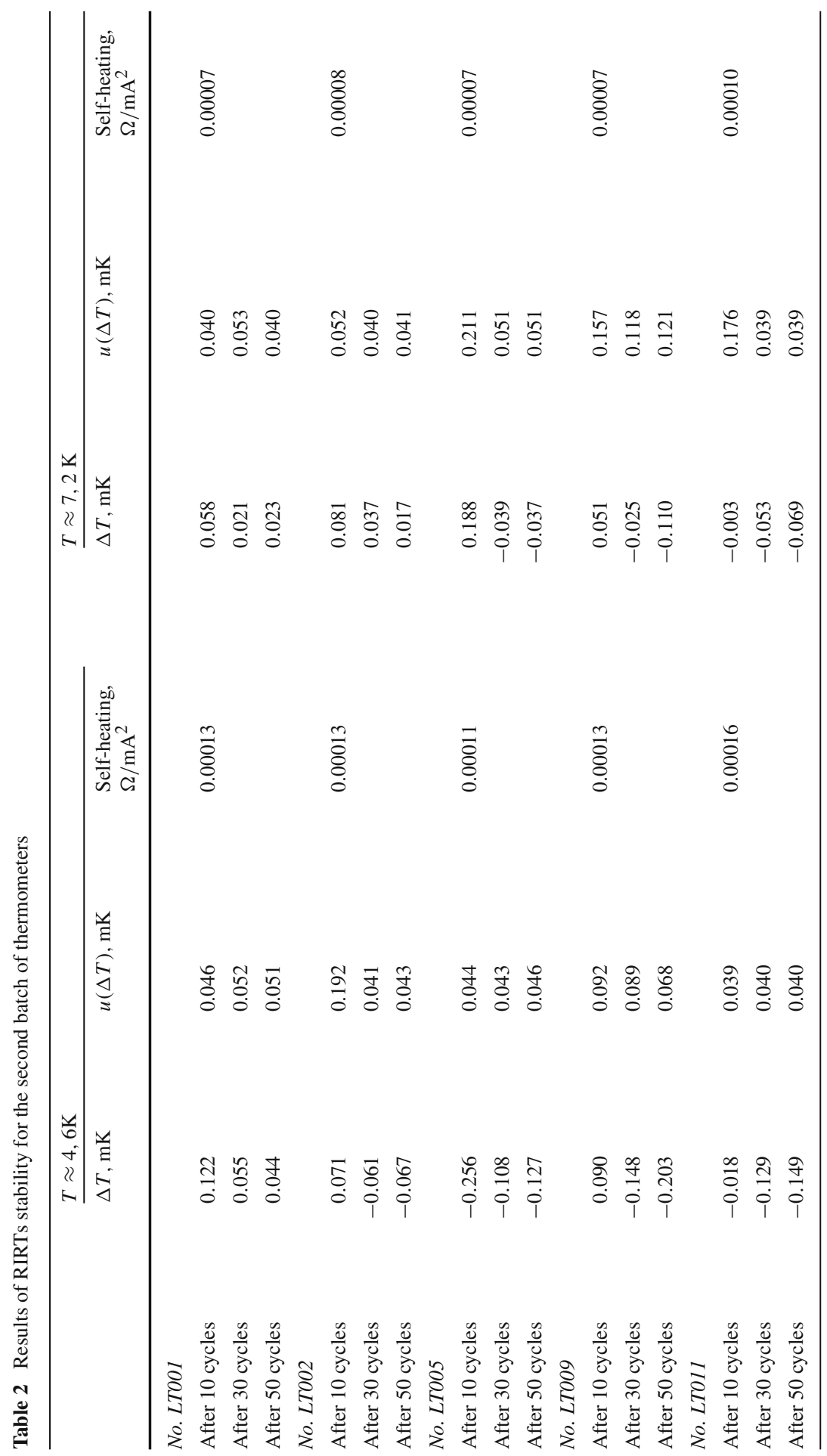




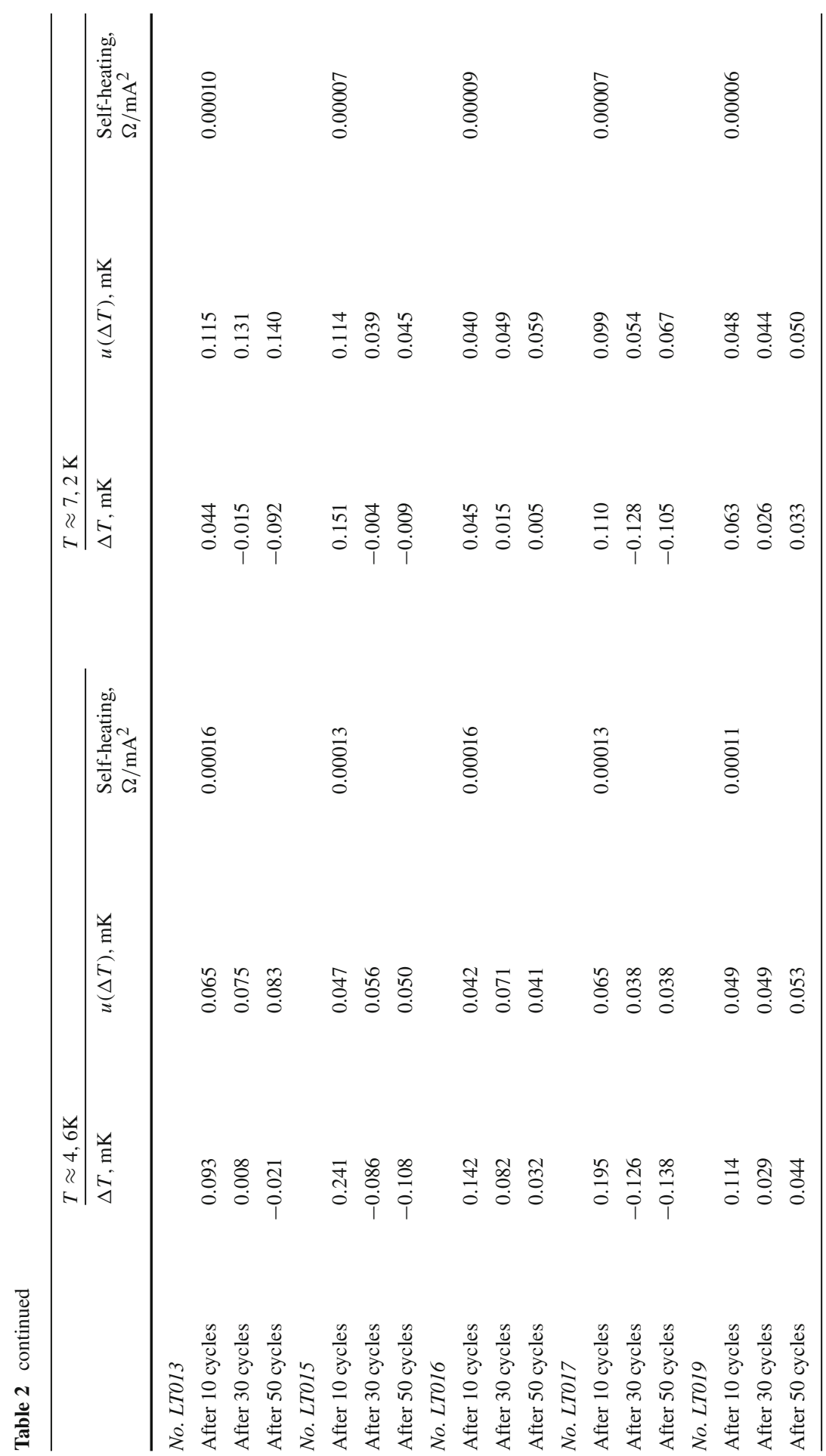




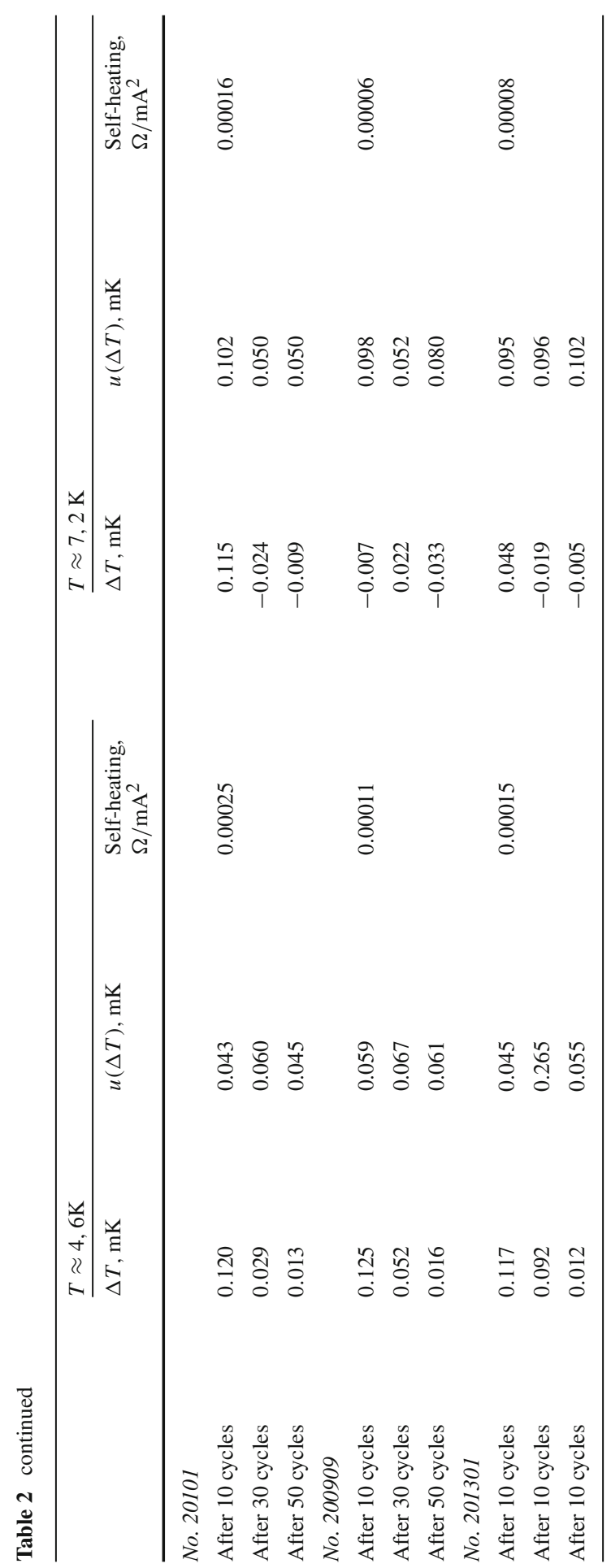


Fig. 1 Liquid helium cryostat construction ( $a$ heat switch, $b$ copper block, $c$ thermal shield, $d$ carbon thermometer, $e$ lead sample, $f$ mutual induction coils)

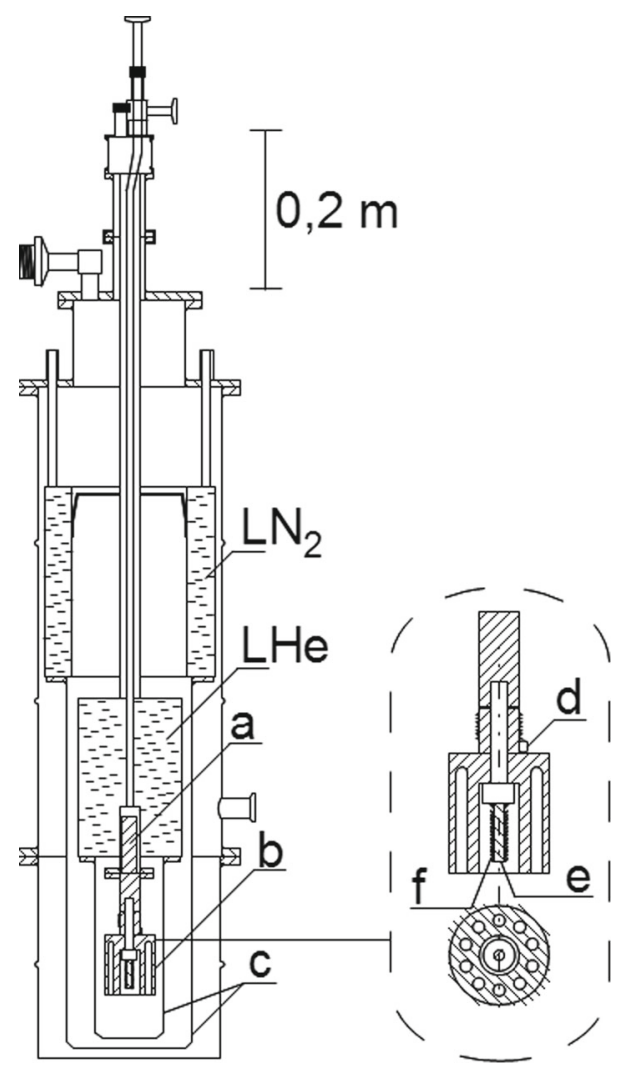

a thermal shield, $c$. Thermal contact between the thermometers and the block was ensured with Apiezon grease. A photograph of the copper block is presented in Fig. 2.

For controlling the temperature of the copper block near $4.6 \mathrm{~K}$, a model 370 Lake Shore Cryotronics temperature controller, with an Allen-Bradley carbon resistance thermometer, $d$ (Fig. 1) was applied. The temperature of the block was stable within $\pm 0.1 \mathrm{mK}$ during the thermometer tests.

At a temperature close to $7.2 \mathrm{~K}$, some tests were carried out with a superconducting lead $(\mathrm{Pb})$ transition (the lead sample, $e$, is shown in Fig. 1) used for the temperature stabilization. The lead sample was inside mutual inductance coils, $f$. The signal from the coil was measured via a lock-in amplifier and transmitted to the PID controller. Because the accuracy of the temperature stabilization using this method was the same as obtained with the Lake Shore Controller, the second simpler methods were used for most tests.

\section{RIRT Resistance Measurements}

The measuring system is shown in Fig. 3. A Measurements International Model MI 6015 bridge (with a measurement uncertainty of 0.02 parts per million) was used 
Fig. 2 Copper block with RIRTs

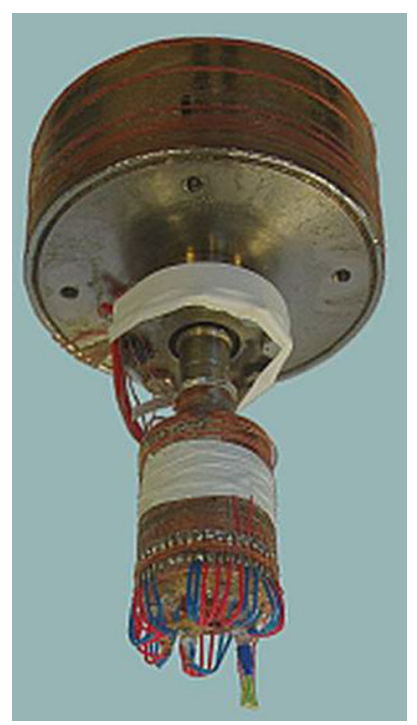

for the resistance measurements. The resistance $R_{\mathrm{X}}$ of each tested thermometer was measured using the standard thermometer no B178, placed in the copper block, as the reference resistor. This method reduces the error due to the temperature drift of the copper block, because both $R_{\mathrm{X}}$ and the resistance $R_{\mathrm{T}}$ of thermometer B178 have similar temperature coefficients, so the ratio $R_{\mathrm{X}} / R_{\mathrm{T}}$ is nearly independent of temperature [11]. The resistance $R_{\mathrm{T}}$ was measured twice-before and after measuring the resistance ratios $R_{\mathrm{X}} / R_{\mathrm{T}}$ of all of the tested thermometers. From these measurements, the values of $R_{\mathrm{T}}$ and the $R_{\mathrm{X}}$ can be calculated and they apply at the mean temperature of thermometer B178.

The resistance $R_{\mathrm{T}}$ was measured relative to a $10 \Omega$ Tinsley standard resistor placed in a thermal enclosure outside the cryostat. The ratio resistance bridge and the standard resistor were calibrated at the Central Office of Measures (the National Measurement Institute in Poland).

The resistance $R_{\mathrm{T}}$ and the ratios $R_{\mathrm{X}} / R_{\mathrm{T}}$ were measured at two currents, $I_{1}=1 \mathrm{~mA}$ and $I_{2}=\sqrt{ } 2 \mathrm{~mA}$, and extrapolated to $I_{0}=0$. All numerical values of the resistances were the average of 40 measurements.

\section{Tests of Thermometers Stability}

To analyze the thermometer stability, we assumed that in a narrow temperature rangewithin about $10 \mathrm{mK}$ - the dependence of $R=f(T)$ for the tested thermometers was linear with sufficient accuracy:

$$
R=a T+b
$$

The $a$ and $b$ coefficients for each thermometer were determined in the first run before the thermal treatments. The resistance $R_{X}$ was measured at three temperatures differ- 


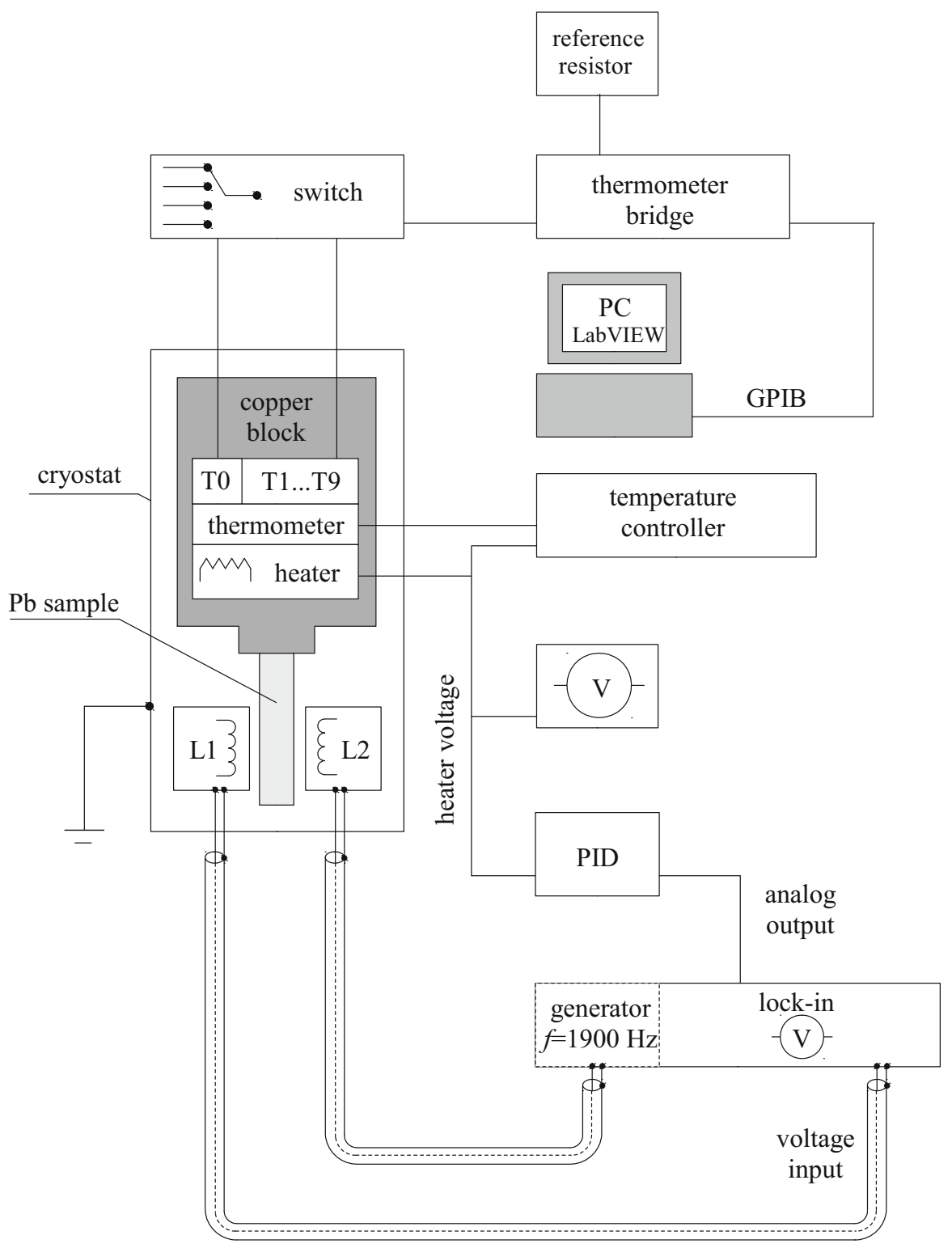

Fig. 3 Measuring system

ing by a few $\mathrm{mK}$, and the linear regression function was applied to calculate $a$ and $b$ coefficients (Fig. 4, solid line). After the thermal treatments, the resistance was measured at two temperatures and the relation $R_{1}=f(T)$ was determined assuming that the linear relationship $R_{1}=a T+b_{1}$ is parallel to $R=a T+b$. The thermometer's stability is expressed by the temperatures difference $T^{\prime \prime}-T^{\prime}$ determined for two points 
Fig. 4 Method of estimation of RIRTs stability

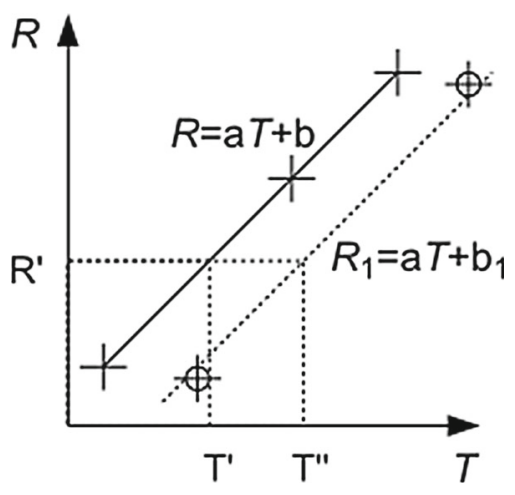

with the same value of resistance $R^{\prime}$ (see Fig. 4) after 10, 30 and 50 thermal cycles. The $T^{\prime \prime}-T^{\prime}$ value was calculated from the equation:

$$
T^{\prime \prime}-T^{\prime}=\frac{b-b_{1}}{a} .
$$

\section{Measurements Results}

The results obtained for the stability of the RIRTs at the temperatures of about $4.36 \mathrm{~K}$ and 7.2 $\mathrm{K}$ for the first and $4.6 \mathrm{~K}$ and $7.2 \mathrm{~K}$ for the second batch of thermometers are presented in Tables 1 and 2, respectively. The values of the uncertainty and self-heating effect are given too. The uncertainty budget included the following components:

- standard error of regression (function $R=a T+b$ ),

- uncertainty of determination of the self-heating corrections,

- uncertainty of ratio bridge,

- standard resistor thermal drift,

- standard thermometer reproducibility.

The results for some selected thermometers are presented in Figs. 5, 6, 7, 8 and 9. The thermometer numbers 20107, 200912 and 20108 were sent to INTiBS in the first batch, and the thermometer number 20101 and LT011 in second one, respectively.
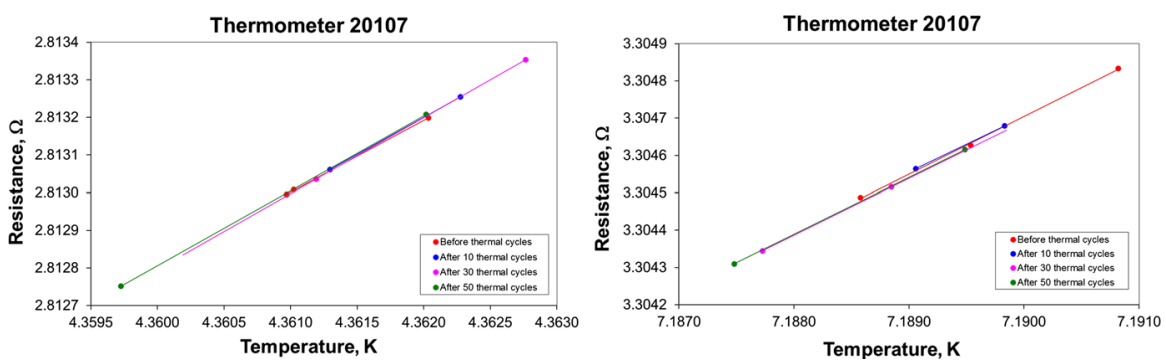

Fig. 5 Graph of resistance versus temperature for thermometer 20107 

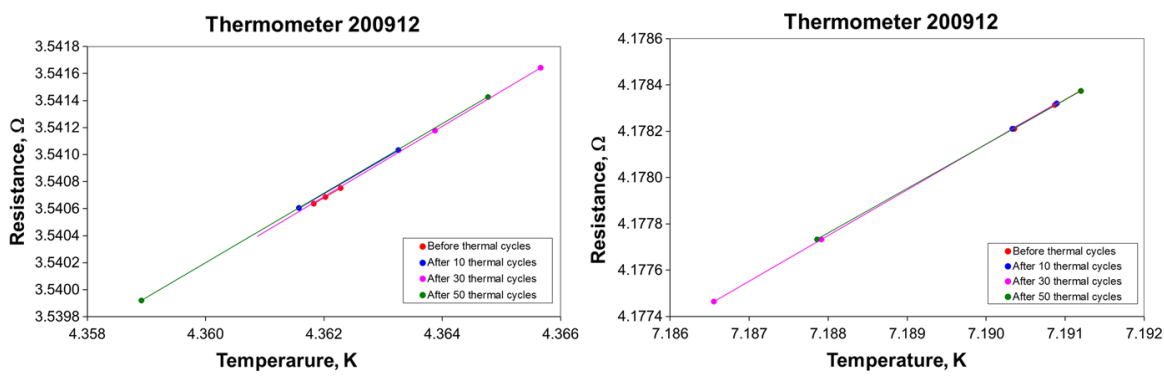

Fig. 6 Graph of resistance versus temperature for thermometer 200912
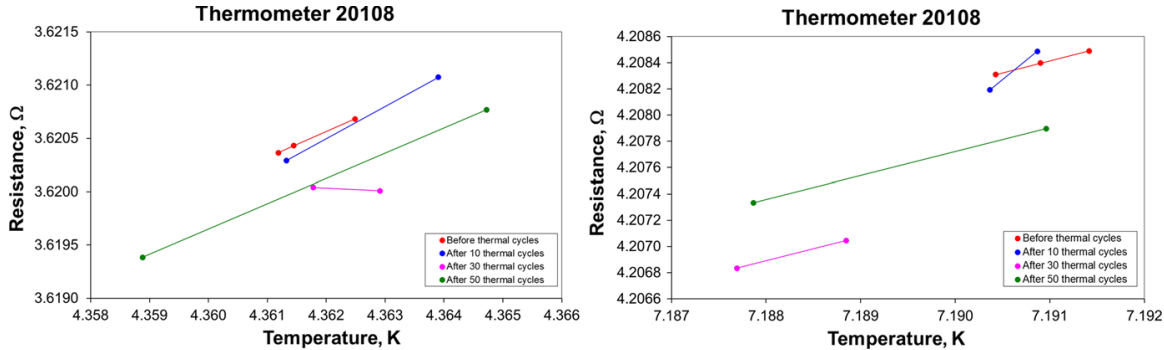

Fig. 7 Graph of resistance versus temperature for thermometer 20108
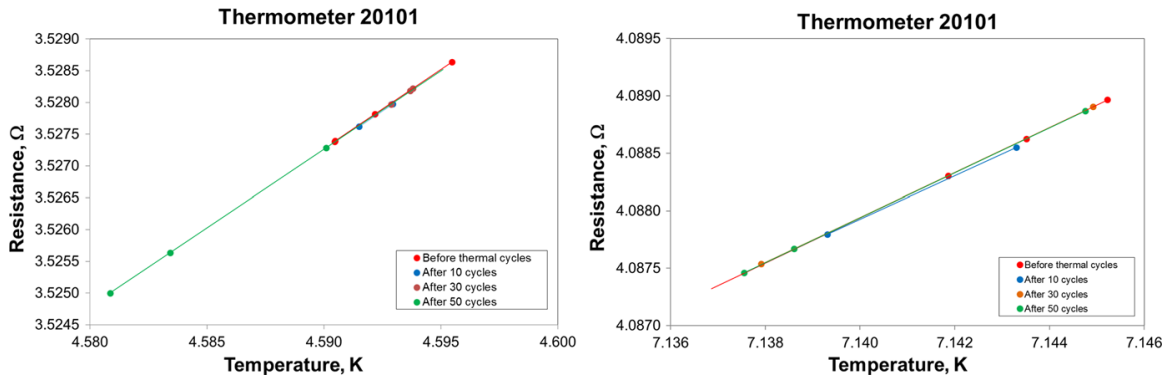

Fig. 8 Graph of resistance versus temperature for thermometer 20101
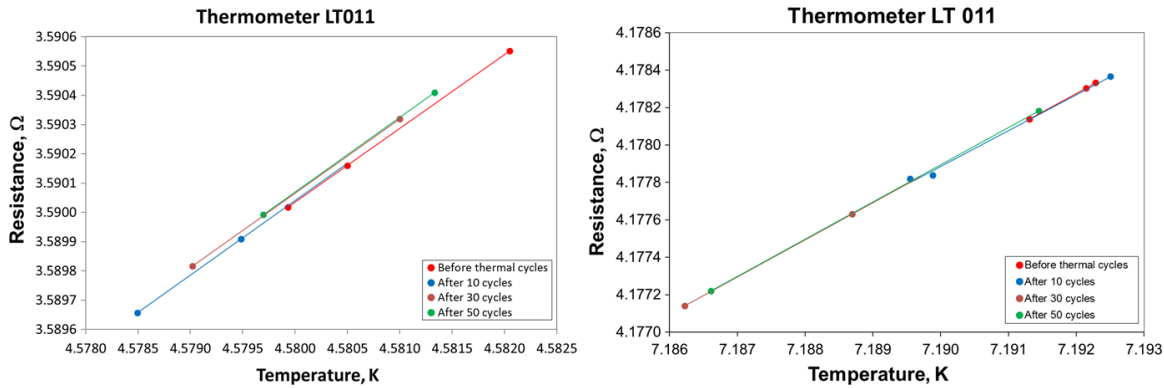

Fig. 9 Graph of resistance versus temperature for thermometer LT011 


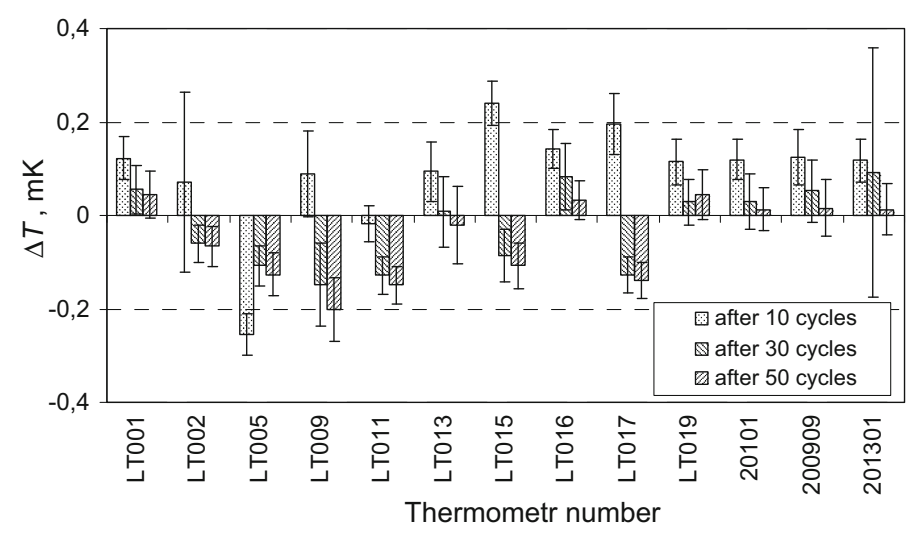

Fig. 10 Stability of second batch RIRTs in $4.6 \mathrm{~K}$

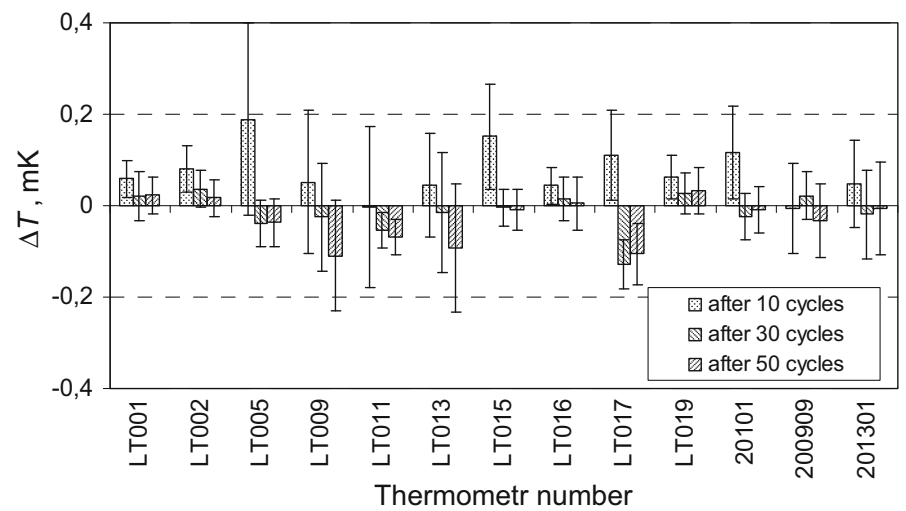

Fig. 11 Stability of second batch RIRTs in $7.2 \mathrm{~K}$

It can be noticed that the stability of thermometer 20108 is worse than the other four, and this is probably related to the larger self-heating, see Table 1. It seems likely that this is due to a small leak in the capsule.

The stability of the second batch of thermometers is shown in Figs. 10 and 11. The stability results of thermometers which showed large self-heating were unreliable, and they are not included in the figures.

\section{Summary}

The studies carried out at INTiBS showed that the majority of the tested RIRTs produced by TIPC are very stable-within $0.2 \mathrm{mK}$ - after thermal cycling treatment between the room and liquid helium temperatures. After first 10 cooling runs the $T^{\prime \prime}-T^{\prime}$ value was larger, but subsequent cycles of thermal treatment stabilized the RIRTs within the range $0.2 \mathrm{mK}$ compared with the indication before thermal treatment. 
Acknowledgements Authors of the paper express thanks to Dr. L. Lipinski from INTiBS for his contribution to the elaboration of the research results.

Open Access This article is distributed under the terms of the Creative Commons Attribution 4.0 International License (http://creativecommons.org/licenses/by/4.0/), which permits unrestricted use, distribution, and reproduction in any medium, provided you give appropriate credit to the original author(s) and the source, provide a link to the Creative Commons license, and indicate if changes were made.

\section{References}

1. W.L. Tew, R.L. Rusby, P. Lin, L. Lipiński, P.P.M. Steur, B.W.A. Ricketson, Int. J. Thermophys. 36, 2036 (2015)

2. R.L. Rusby, in Temperature, Its Measurements and Control in Science and Industry, Part 2, ed. by H.H. Plumb (ISA, Pittsburgh, 1972), p. 865

3. R.L. Rusby, in Temperature, Its Measurements and Control in Science and Industry, Part 1, ed. by J.F. Schooley (AIP, New York, 1982), p. 829

4. L.M. Besley, P. Lin, Meas. Sci. Technol. 4, 1357 (1993)

5. G.A. Kytin, S.F. Vorfolomeev, Y.A. Dedikov, L.N. Ermilova, D.N. Astrov, in Proceedings of the 17th Meeting of the CCT, Document 89-7 (BIPM, Sevres, 1989)

6. O. Tamura, H. Sakurai, Jpn. J. Appl. Phys. 26, L947 (1987)

7. P. Lin, Acta Metrol. Sin. 29, 171 (2008)

8. P. Lin, X. Li, B. Gao, L. Yu, R. Huang, F. Li, Development of Chinese standard type of rhodium-iron resistance thermometers, in Presented on XIII International Symposium on Temperature and Thermal measurements in Industry and Science TEMPMEKO 2016, Zakopane (2016)

9. F. Pavese, A. Szmyrka-Grzebyk, L. Lipiński, H. Manuszkiewicz, P. Qiu, J.T. Zhang, P. Lin, X.W. Li, Int. J. Thermophys. 29, 51 (2008)

10. L. Lipiński, A. Szmyrka-Grzebyk, P. Lin, X.W. Li, H. Manuszkiewicz, D. Jancewicz, A. Grykalowska, P.P.M. Steur, F. Pavese, Int. J. Thermophys. 31, 1696 (2010)

11. V. Batagelj, J. Bojkovski, Int. J. Thermophys. 32, 1409-1417 (2011) 